\title{
Increasing ambient operating theatre temperature and wrapping in polyethylene improves admission temperature in premature infants
}

\author{
Alison L Kent ${ }^{1,2}$ and Jeni Williams ${ }^{3}$ \\ ${ }^{1}$ Department of Neonatology, ${ }^{3}$ Neonatal Nursing Division, The Canberra Hospital and ${ }^{2}$ Australian National University Medical School, Canberra, ACT, Australia
}

\begin{abstract}
Aim: To improve admission temperatures of preterm infants $\leq 31$ weeks gestation by increasing the ambient temperature in the operating theatre and wrapping in polyethylene wrap at caesarean section.

Methods: A review of admission temperature of infants with gestational age $\leq 31$ weeks from January 2000 to July 2002 was performed. Between October 2002 and 2003 the ambient operating theatre temperature was increased to $26-28^{\circ} \mathrm{C}$ for deliveries $\leq 27$ weeks gestation and to $25^{\circ} \mathrm{C}$ for deliveries $\geq 28$ weeks gestation. From September 2004 to December 2005 the ambient theatre temperature was increased along with wrapping infants in polyethylene. A clinical audit cycle review of admission temperatures and early morbidity and mortality was undertaken. Results: 156 premature infants were included, $42<28$ weeks and $11428-31$ weeks gestation. The mean admission temperature in $<28$ weeks infants prior to intervention was $35.3^{\circ} \mathrm{C}$, after increasing ambient theatre temperature $35.9^{\circ} \mathrm{C}$, and after increasing ambient temperature and using polyethylene wrap $37.0^{\circ} \mathrm{C}(P<0.0001)$. For infants $28-31$ weeks the mean admission temperatures in the three epochs were $36.3^{\circ} \mathrm{C}$, $36.5^{\circ} \mathrm{C}$ and $36.6^{\circ} \mathrm{C}$, respectively $(P=0.002)$. There was no statistically significant difference in: total days of ventilation or oxygen, definite necrotising enterocolitis, intraventricular haemorrhage grade 3 or 4 or survival.

Conclusions: Increasing the ambient temperature in the operating theatre and wrapping premature infants in polyethylene wrap improves admission temperature. Further studies are required to determine whether these interventions are associated with improved outcome in the premature neonate.
\end{abstract}

Key words: hypothermia; operating theatre; polyethylene; premature; temperature.

Much is now known regarding heat loss from the newborn infant and the effects on energy consumption. Adamsons et al. described the influence of temperature on oxygen consumption in term newborn infants as well as the rate of temperature loss over time if no immediate action was taken to reduce heat loss. ${ }^{1,2}$ In the late 1950 s Silverman et al. provided evidence that hypothermia increased morbidity and mortality. ${ }^{3-5}$ Hypothermia continues to be a significant problem in the extremely premature infant. ${ }^{6,7}$

\section{Key Points}

1 Increasing ambient operating theatre temperature and wrapping infants in polyethylene wrap improves admission temperature in premature infants.

2 A multidisciplinary education programme can successfully achieve an improvement in clinical practice.

3 Further large studies are required to determine whether improving admission temperature improves mortality and morbidity.

Correspondence: Dr Alison Kent, Department of Neonatology, The Canberra Hospital, PO Box 11, Woden 2606, ACT, Australia. Fax: +61 26244 3112; email: alison.kent@act.gov.au

Accepted for publication 14 October 2007.
The clinical implications of cold stress include: hypoglycaemia, respiratory distress, hypoxia, metabolic acidosis, coagulation defects, persistent fetal circulation, acute renal failure, necrotizing enterocolitis, weight loss and failure to increase weight, and in extreme cases death. ${ }^{8-13}$ The World Health Organisation (WHO) has classified mild hypothermia as a core temperature of $36-36.4^{\circ} \mathrm{C}$, moderate hypothermia as $32-35.9^{\circ} \mathrm{C}$ and severe as less than $32^{\circ} \mathrm{C} .{ }^{14}$ Attempts are required to minimise heat loss via the four means of heat exchange - conduction, convection, radiation and evaporation. This can be done by pre-warming resuscitation surfaces to reduce conductive losses as well as providing radiant heat. By increasing ambient theatre temperatures a reduction in heat loss via convection may occur, and drying or wrapping infants may reduce evaporative losses.

A Cochrane review of interventions to prevent hypothermia at birth in preterm and/or low-birth-weight infants has been performed..$^{15}$ The review looked at plastic wraps or bags, skinto-skin care and transwarmer mattresses, and determined that all methods led to higher admission temperatures, but there was limited data available on long-term outcome. Cramer et al. had similar findings in their systematic review of occlusive wraps for premature infants. ${ }^{16}$

The WHO has suggested that the delivery room temperature should be $25^{\circ} \mathrm{C}$, at a minimum. ${ }^{14}$ Knobel et al. in their study 
Table 1 Demographic data of infants born by caesarean section over the three epochs

\begin{tabular}{|c|c|c|c|c|}
\hline & $\begin{array}{l}\text { Epoch one } \\
\text { July } 2000 \text { to } \\
\text { July } 2002 \\
n=73\end{array}$ & $\begin{array}{l}\text { Epoch two } \\
\text { November } 2002 \text { to } \\
\text { October } 2003 \\
n=35\end{array}$ & $\begin{array}{l}\text { Epoch three } \\
\text { September } 2004 \text { to } \\
\text { December } 2005 \\
n=48\end{array}$ & $P$-value \\
\hline Mean birthweight $(g)^{*}(S D)$ & 1235 (397) & 1097 (494) & $1194(297)$ & 0.24 \\
\hline Mean gestation (weeks)* (SD) & $28.9(2.4)$ & $28.4(2.5)$ & $28.9(1.8)$ & 0.56 \\
\hline Male gender number $(\%)^{* *}$ & $28(38.4)$ & $18(51.4)$ & $28(58.3)$ & 0.09 \\
\hline Mean Apgar 1 min* (SD) & $6.1(2.3)$ & $5.6(2.2)$ & $5.3(2.2)$ & 0.16 \\
\hline Mean Apgar 5 min* (SD) & $7.8(1.6)$ & $7.6(1.8)$ & $7.6(1.8)$ & 0.72 \\
\hline Antenatal steroids number** (\%) & $45(61.6)$ & $23(65.7)$ & 35 (72.9) & 0.44 \\
\hline
\end{tabular}

found that the combination of wrapping in a polyurethane bag and increasing the ambient theatre temperature improved admission temperatures. ${ }^{17}$

The aim of this study was to improve admission temperatures of preterm infants $\leq 31$ weeks gestation by increasing the ambient temperature in the operating theatre and wrapping in polyethylene wrap at caesarean section.

\section{Methods}

A retrospective review of admission temperatures of infants admitted to the Neonatal Intensive Care Unit was performed over three epochs. As this was a retrospective audit, a formal ethics application was not required as per NHMRC guidelines; however, approval for access to the medical records for the study was given by the hospital administration. Data were acquired from the neonatal intensive care unit database, any further information was obtained from the hospital electronic medical record. The database is a prospectively managed database which is completed at the time of discharge of the infant from the neonatal intensive care unit.

The first epoch was from July 2000 to July 2002 prior to any changes in clinical practice. At this time the operating theatre temperature was set at $20^{\circ} \mathrm{C}$, the infant was placed under a radiant warmer, dried and wrapped with warm blankets. From November 2002 to October 2003 a clinical change was introduced increasing the ambient operating theatre temperature to $26-28^{\circ} \mathrm{C}$ for deliveries $\leq 27$ weeks gestation and to $25^{\circ} \mathrm{C}$ for deliveries $\geq 28-35$ weeks gestation. The operating theatre temperature was increased and at a stable temperature prior to commencement of the caesarean section. This change in clinical practice involved an educational programme including Neonatologists, neonatal nursing staff, midwifery staff, obstetricians, operating theatre staff and anaesthetists. A further change in clinical practice was introduced in September 2004 that combined increasing the ambient operating theatre temperature with wrapping of the infant in polyethylene. Data were collected during this third epoch on whether both interventions had taken place. Admission temperatures were taken per axilla using the Terumo digital clinical thermometer C202.

Data collected included: gestation, birthweight, admission temperature, survival, total days of ventilation (including nasal continuous positive airway pressure), days of oxygen, definite necrotising enterocolitis (NEC) (abdominal X-ray changes consistent with NEC, fresh rectal bleeding or perforation), intraventricular haemorrhage (IVH) grade III or IV and late infection.

Delivery rooms in this hospital can be warmed but not to a precise temperature. However, during this period of education on thermal protection of the neonate and the commencement of wrapping all premature infants with polyethylene wrap, a difference in admission temperatures may have occurred for vaginal deliveries.

Data were stored and analysed using SPSS 15.01 database. Figures were produced using SPSS 15.01. Differences between admission temperatures across the three epochs were assessed using the Kruskal-Wallis test. Analysis of variance was used to examine differences across the epochs for gestational age, birthweight, Apgar scores at 1 and 5 min, days of ventilation and days of oxygen. Chi-squared tests were used to examine gender, antenatal steroids, survival, NEC, IVH and late infection across the three epochs. A generalized linear model was used to examine the interaction effects of gestational age and birthweight and admission temperature with the three epochs. Correlations between birthweight and admission temperature were assessed using the Pearson product moment correlation.

\section{Results}

Two hundred and ninety-nine babies less than 32 weeks gestation were admitted during these three epochs, 156 (52\%) of which were delivered by caesarean section. The demographics of the infants across the three epochs are provided in Table 1. There were no significant differences in the infants between the three epochs. A subanalysis of groups was performed with infants between 24 and 27 weeks gestation and between 28 and 31 weeks gestation.

\section{Caesarean section deliveries}

The mean admission temperature in infants between 24 and 27 weeks gestation during the first epoch prior to any changes in clinical practice was $35.3^{\circ} \mathrm{C}$. During the second epoch the mean admission temperature increased to $35.9^{\circ} \mathrm{C}$ and during 
Table 2 Mean admission temperatures of infants in the three epochs in gestational age groups 24-27 weeks and 28-31 weeks gestation

\begin{tabular}{|c|c|c|c|c|}
\hline & $\begin{array}{l}\text { Epoch one } \\
\text { July } 2000 \text { to } \\
\text { July } 2002\end{array}$ & $\begin{array}{l}\text { Epoch two } \\
\text { November } 2002 \\
\text { to October } 2003\end{array}$ & $\begin{array}{l}\text { Epoch three } \\
\text { September } 2004 \text { to } \\
\text { December } 2005\end{array}$ & $P$-value \\
\hline Mean admission temperature & $n=17$ & $n=15$ & $n=10$ & \\
\hline 24-27 weeks gestation $\left({ }^{\circ} \mathrm{C}\right)^{*}(\mathrm{SD})$ & $35.3(0.98)$ & $35.9(1.0)$ & $37.0(0.65)$ & $<0.0001$ \\
\hline Mean admission temperature & $n=56$ & $n=20$ & $n=38$ & \\
\hline 28-31 weeks gestation $\left({ }^{\circ} \mathrm{C}\right) *(\mathrm{SD})$ & $36.3(0.57)$ & $36.5(0.44)$ & $36.6(0.5)$ & 0.005 \\
\hline
\end{tabular}

Table 3 Morbidity and mortality across the three epochs

\begin{tabular}{|c|c|c|c|c|}
\hline & $\begin{array}{l}\text { Epoch one } \\
\text { July } 2000 \text { to } \\
\text { July } 2002 \\
n=73\end{array}$ & $\begin{array}{l}\text { Epoch two } \\
\text { November } 2002 \text { to } \\
\text { October } 2003 \\
n=35\end{array}$ & $\begin{array}{l}\text { Epoch three } \\
\text { September } 2004 \text { to } \\
\text { December } 2005 \\
n=48\end{array}$ & $P$-value \\
\hline Survive (\%)* & $63(86)$ & $29(83)$ & $43(90)$ & 0.67 \\
\hline Mean total days ventilation $(S D)^{\star \star}$ & $18(30)$ & $25(30)$ & $23(26)$ & 0.4 \\
\hline Mean days oxygen $(\mathrm{SD})^{\star \star}$ & $33(41)$ & $56(69)$ & $34(36)$ & 0.07 \\
\hline Definite NEC $(\%)^{\star}$ & $4(5.5)$ & $4(11.0)$ & $2(4.2)$ & 0.35 \\
\hline IVH III/IV (\%)* & $6(8.2)$ & $1(3)$ & $1(2.1)$ & 0.42 \\
\hline Late infection $(\%)^{*}$ & $17(23)$ & $15(43)$ & $13(27)$ & 0.1 \\
\hline
\end{tabular}

${ }^{\star}$ Chi-square test, $P<0.05$ significant. ${ }^{\star *}$ Kruskal- Wallis test, $P<0.05$ significant. IVH, intraventricular haemorrhage; NEC, necrotising enterocolitis.

the third epoch increased to $37.0^{\circ} \mathrm{C}$ (Kruskal-Wallis $P<0.0001)$. The range of temperatures in the first epoch was $32.8-36.4^{\circ} \mathrm{C}$ with only $18 \%$ (3/17) having an admission temperature of $36.4^{\circ} \mathrm{C}$. In the second epoch the range of temperatures was $34.5-38.4^{\circ} \mathrm{C}$ with $27 \%(4 / 15)$ having an admission temperature of $36.4^{\circ}$ or above. Only one infant had a temperature above $37.5^{\circ} \mathrm{C}$. During the third epoch the range of temperature on admission was $36.0-37.8^{\circ} \mathrm{C}$ with $80 \%(8 / 10)$ having an admission temperature of $36.4^{\circ} \mathrm{C}$ or above. Two infants had an admission temperature above $37.5^{\circ} \mathrm{C}$.

In infants between 28 and 31 weeks gestation the mean admission temperature in the first epoch was $36.3^{\circ} \mathrm{C}$ and increased significantly over the three epochs (Kruskal-Wallis $P=0.005$ ) (Table 2). The range of admission temperature in the first epoch was $34.7-38.0^{\circ} \mathrm{C}$ with $46 \%(26 / 56)$ having an admission temperature $36.4^{\circ} \mathrm{C}$ or above. Only one infant had a temperature above $37.5^{\circ} \mathrm{C}$. During the second epoch the range of temperatures was $35.8-37.2^{\circ} \mathrm{C}$ with $60 \%(12 / 20)$ having an admission temperature above $36.4^{\circ} \mathrm{C}$. In the third epoch the temperature on admission ranged from $35.0^{\circ} \mathrm{C}$ to $37.8^{\circ} \mathrm{C}$ with $79 \%(30 / 38)$ having an admission temperature above $36.4^{\circ} \mathrm{C}$. Only one infant had an admission temperature above $37.5^{\circ} \mathrm{C}$.

There were no significant differences in survival, total days of ventilation, days of oxygen, definite NEC, IVH grade III or IV and late infection (Table 3).

There was a significant interaction between birthweight and gestational age with the three epochs in admission temperature
$(P=0.04, P=0.004)$. In the first and second epoch there was a correlation between birthweight and admission temperature $(P<0.0001$ and $P<0.009$, respectively). However, in the third epoch combining increased ambient operating theatre temperature and wrapping with polyethylene, this correlation no longer existed $(P=0.26)$. This was also seen for gestational age and admission temperature across the three epochs $(P<0.0001$, $P=0.03, P=0.5$, respectively). Scatter plots of birthweight and gestational age with admission temperature are provided in Figures 1 and 2 .

\section{Vaginal deliveries}

During the study period the gestation and birthweight were significantly higher than in the third epoch than the first two epochs $(P=0.012$ and $P=0.005$, respectively). In infants with a gestation between 24 and 27 weeks gestation the mean admission temperature did increase over the three epochs $\left(35.6^{\circ} \mathrm{C}\right.$, $\left.35.8^{\circ} \mathrm{C}, 35.9^{\circ} \mathrm{C}\right)$, but was not statistically significant $(P=0.6)$. This was also true for infants between 28 and 31 weeks gestation $\left(36.5^{\circ} \mathrm{C}, 36.6^{\circ} \mathrm{C}, 36.7^{\circ} \mathrm{C} ; P=0.17\right)$. However, there was an increase in the proportion of infants with an admission temperature of $36.4^{\circ} \mathrm{C}$ or above between the first and second epoch ( $16.7 \%$ to $47 \%)$, but this was not seen in the third epoch, in which there were only four infants less than 28 weeks gestation. The proportion of infants with an admission temperature equal 
(a)

Epoch One

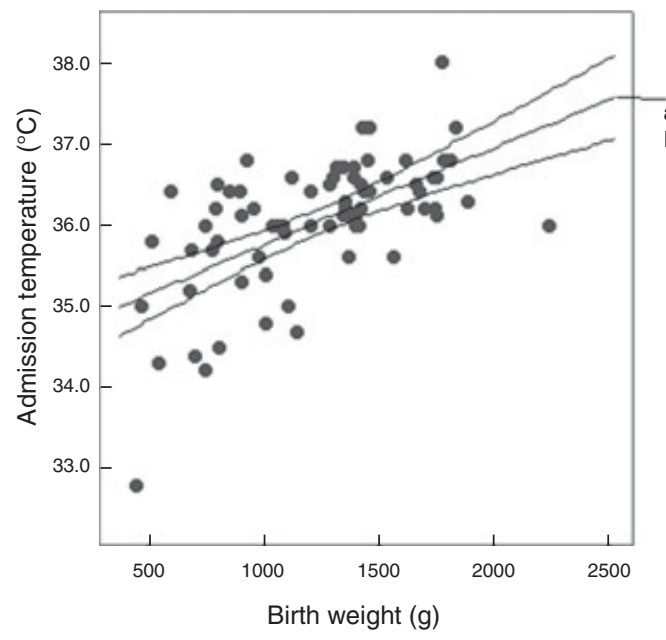

(b) Epoch Two

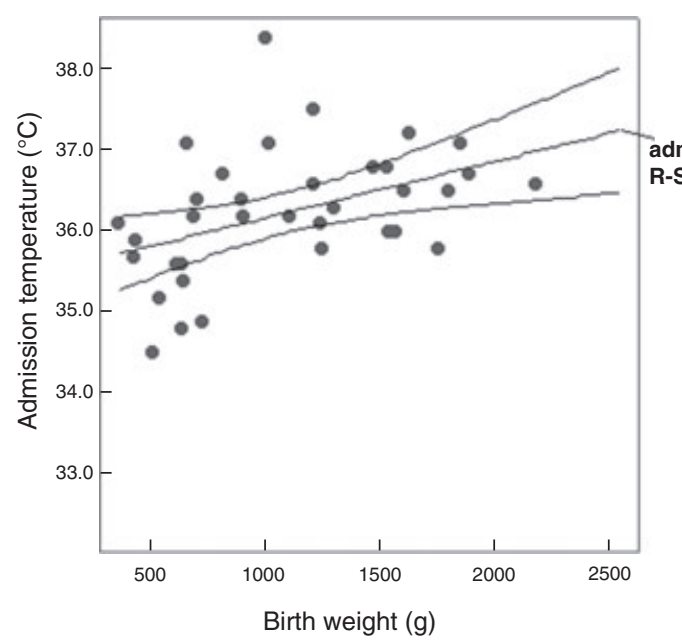

(c)

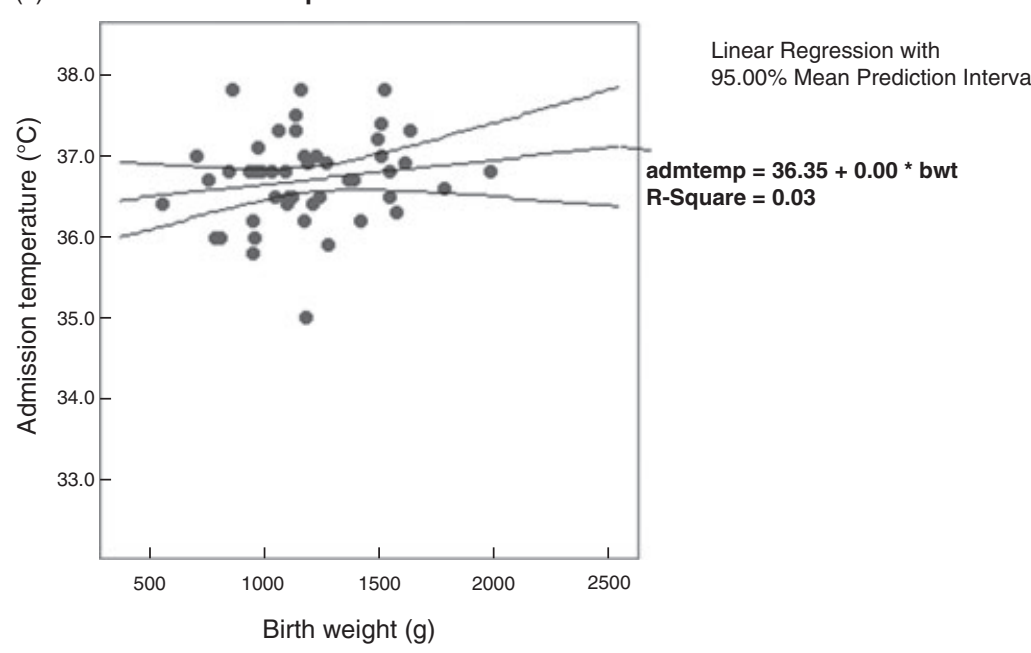

Linear Regression with

95.00\% Mean Prediction Interval

admtemp $=34.58+0.00$ * bwt

$\mathrm{R}$-Square $=\mathbf{0 . 3 5}$

Linear Regression with

95.00\% Mean Prediction Interval admtemp $=35.48+0.00 *$ bwt

$\mathrm{R}-\mathrm{Square}=\mathbf{0 . 1 9}$

Fig. 1 Scatterplot of birth weight and admission temperature for the three epochs. 
(a)

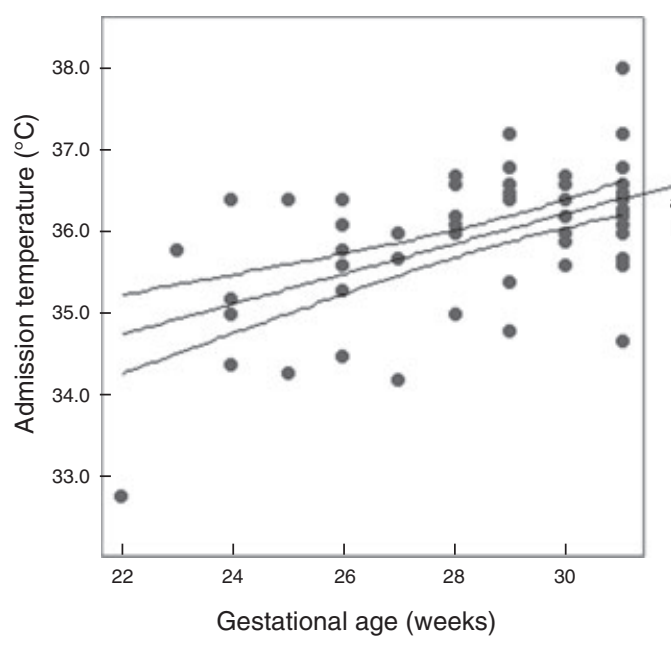

(b)

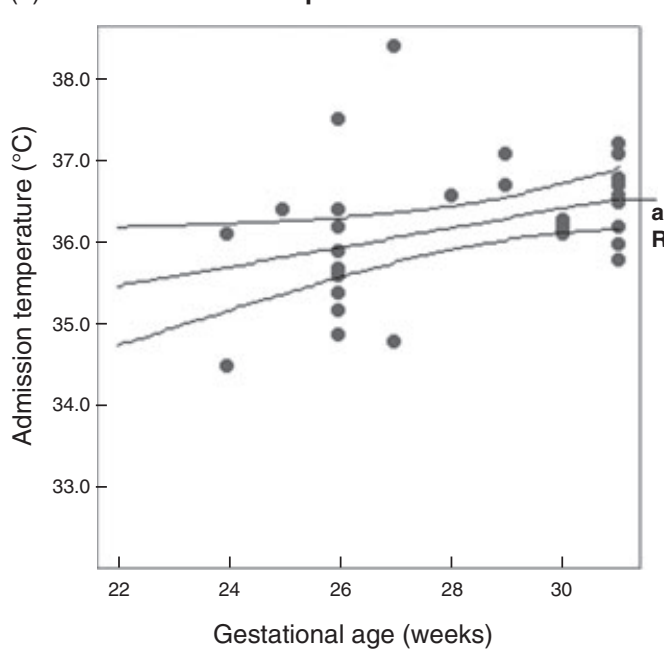

(c)
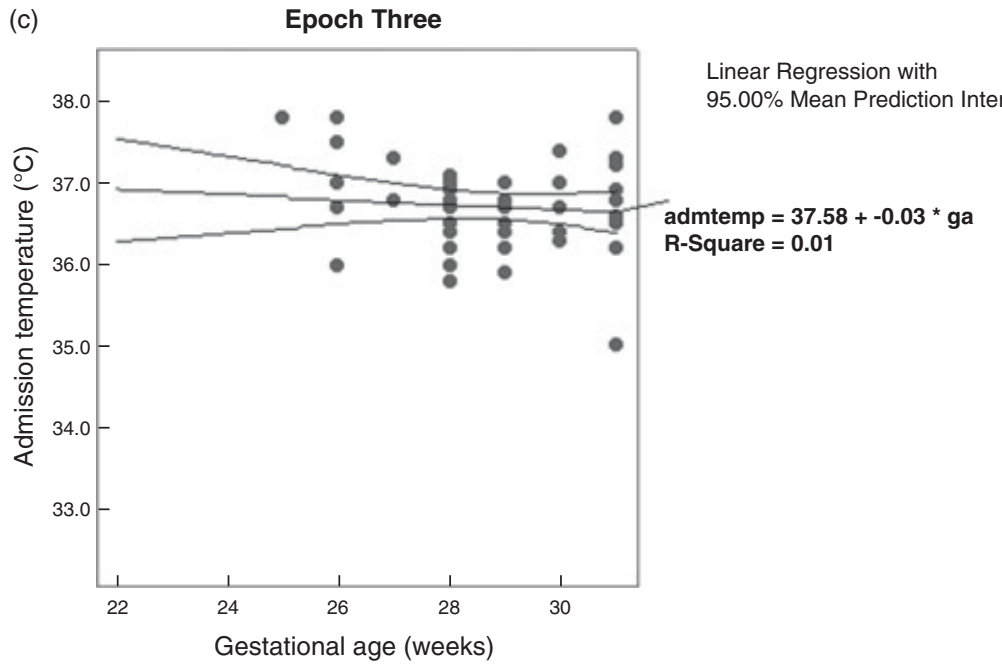

Linear Regression with

95.00\% Mean Prediction Interval

admtemp $=30.72+0.18$ * ga

R-Square $=0.31$

Linear Regression with

95.00\% Mean Prediction Interval

admtemp $=32.87+0.12$ * ga

R-Square $=0.14$
Fig. 2 Scatterplot of gestational age and admission . 
to or above $36.4^{\circ} \mathrm{C}$ increased over the three epochs for infants $28-31$ weeks gestation $(60.8 \%, 68.7 \%$ and $74.2 \%$, respectively).

\section{Discussion}

This clinical audit cycle confirms the findings of other studies that increasing the ambient operating theatre temperature and wrapping infants in polyethylene can increase admission temperatures. Involvement of all disciplines in the education process most likely resulted in the success of this change in clinical practice. This study is limited by its retrospective nature; however, the database from which the information is collected is managed prospectively.

Vohra et al. have performed two randomised trials using polyethylene occlusive skin wrapping to prevent heat loss in premature infants, both showing an improvement in admission temperatures. ${ }^{18,19}$ They found a positive correlation between birthweight and admission temperature even with polyethylene wrapping. Our study found that this correlation was lost when increasing the ambient operating theatre temperature was combined with polyethylene wrapping, indicating that it is the extremely low birthweight baby who will benefit most from this combination of practices.

It is important to not overheat neonates, especially those at risk of hypoxic ischaemic encephalopathy. In our study during the first epoch only one case had an admission temperature above $37.5^{\circ} \mathrm{C}$, one patient $(2 \%)$ had a temperature above $37.5^{\circ} \mathrm{C}$ during the second epoch and during the third epoch three cases $(6 \%)$. It is reassuring that these numbers remained low; however, care must be taken to ensure that hyperthermia does not persist following admission to the neonatal intensive care unit.

Involvement of all disciplines was required for this change in clinical practice to be successful. One of the concerns frequently raised by operating theatre staff and surgeons was the concern regarding risk of increased wound infection with increasing the ambient room temperature. There is now a growing body of evidence suggesting that there are a number of benefits of perioperative normothermia including reduced wound infection, reduced hospitalisation, earlier extubation and reduced blood loss, in comparison to allowing mild hypothermia which usually occurs with surgery performed without any warming of the patient or ambient room temperature. ${ }^{20-24}$

Shivering in women about to undergo caesarean section is common, and neuraxial anaesthesia may increase this due to lower body sympathectomy producing core-to-peripheral redistribution of heat. Horn et al. found that with pre-warming prior to epidural insertion and throughout caesarean section that there was decreased maternal shivering and that the neonate had a higher core temperature and umbilical vein $\mathrm{pH} .{ }^{25}$ Given these findings, and improved surgical outcomes with perioperative warming, increasing the ambient operating theatre temperature appears to be of low risk with significant benefit to both the mother and the neonate.

\section{Conclusions}

Increasing the ambient operating theatre temperature and wrapping in polyethylene improves the admission temperature of premature infants, particularly those less than 28 weeks gestation. Larger studies are required to determine whether this results in long-term benefit in respect to mortality and morbidity.

\section{Acknowledgements}

We would like to thank all of the neonatal nursing staff, midwifery staff, obstetricians, operating theatre staff and anaesthetists of The Canberra Hospital who have accepted a change in clinical practice with enthusiasm. We would also like to thank Dr David Todd, Department of Neonatology, The Canberra Hospital for advice regarding the manuscript, Mr Bruce Shadbolt, Clinical Epidemiology Unit, The Canberra Hospital for assistance with statistics and Mr John Edwards, Coder for the Department of Neonatology, The Canberra Hospital for assisting with data extraction.

\section{References}

1 Adamsons K, Gandy GM, James LS. The influence of thermal factors upon oxygen consumption of the newborn human infant. J. Pediatr. 1965; 66: 495-508.

2 Adamsons K, Towell ME. Thermal homeostasis in the fetus and newborn. Anesthesiology 1965; 26: 531-48.

3 Silverman WA, Blanc WA. The effect of humidity on survival of newly born premature infants. Pediatrics 1957; 20: 477-87.

4 Day LD, Caliguiri L, Kamenski C, Ehrlich F. Body temperature and survival of premature infants. Pediatrics 1964; 34: 171-81.

5 Jolly $\mathrm{H}$, Molyneux $\mathrm{P}$, Newell DJ. A controlled study of the effect of temperature on premature babies. J. Pediatr. 1962; 60: 889-94.

6 Costeloe K, Hennessy E, Gibson AT, Marlow N, Wilkinson AR. The EPICure study: outcomes to discharge from hospital for infants born at the threshold of viability. Pediatrics 2000; 106: 659-71.

7 Laptook AR, Salhab W, Bhaskar B and the Neonatal Research Network. Admission temperature of low birth weight infants: predictors and associated morbidities. Pediatrics 2007; 119: e643-649.

8 Elliott RI, Mann TP. Neonatal cold injury due to accidental exposure to cold. Lancet 1957; 272: 229-34.

9 Pomerance JJ, Madore C. Effect of temperature on survival of infants with RDS. Pediatr. Res. 1974; 8: 449 (Abstract).

10 Gandy GM, Adamsons K, Cunningham N, Silverman WA, James LS. Thermal environment and acid-base homeostasis in human infants during the first few hours of life. J. Clin. Invest. 1964; 43: 751-8.

11 Chadd MA, Gray OP. Hypothermia and coagulation defects in the newborn. Arch. Dis. Child. 1972; 47: 819-21.

12 Stephenson JM, Du JN, Oliver TK Jr. The effect of cooling on blood gas tensions in newborn infants. J. Pediatr. 1970; 76: 848-52.

13 Glass L, Silverman WA, Sinclair JC. Effects of the thermal environment on cold resistance and growth of small infants after the first week of life. Pediatrics 1968; 41: 1033-46.

14 WHO Department of Reproductive Health and Research. Thermal Protection of the Newborn: A Practical Guide (WHO/RHT/MSM/97.2). Geneva: World Health Organisation, 1997.

15 McCall EM, Alderdice FA, Halliday HL, Jenkins JG, Vohra S. Interventions to prevent hypothermia at birth in preterm and/or low birthweight babies. Cochrane Database Syst. Rev. 2005 1: CD004210.

16 Cramer K, Wiebe N, Hartling L, Crumley E, Vohra S. Heat loss prevention: a systematic review of occlusive skin wrap for premature neonates. J. Perinatol. 2005; 25: 763-9.

17 Knobel RB, Wimmer JE, Holbert D. Heat loss prevention for preterm infants in the delivery room. J. Perinatol. 2005; 25: 304-8. 
18 Vohra S, Frent G, Campbell V, Abbott M, Whyte R. Effect of polyethylene occlusive skin wrapping on heat loss in very low birth weight infants at delivery: a randomized trial. J. Pediatr. 1999; 134: 547-51.

19 Vohra S, Roberts RS, Zhang B, Janes M, Schmidt B. Heat loss prevention (HELP) in the delivery room: a randomized controlled tiral of polyethylene occlusive skin wrapping in very preterm infants. J. Pediatr. 2004; 145: 750-3.

20 Kurz A, Sessler DI, Lenhardt R for the study of wound infection and temperature group. Perioperative normothermia to reduce the incidence of surgical-wound infection and shorten hospitalization. N. Engl. J. Med. 1996; 334: 1209-15.

21 Bock M, Muller J, Bach A, Bohrer H, Martin E, Motsch J. Effects of preinduction and intraoperative warming during major laparotomy. $\mathrm{Br}$. J. Anaesth. 1998; 80: 159-63.
22 Melling AC, Ali B, Scott EM, Leaper DJ. Effects of preoperative warming on the incidence of wound infection after clean surgery: a randomized controlled trial. Lancet 2001; 358: 876-80.

23 Vanni SM, Braz JRC, Modolo NSP, Amorim RB, Rodrigues GR Jr. Preoperative combined with intraoperative skin-surface warming avoids hypothermia caused by general anesthesia and surgery. J. Clin. Anesth. 2003; 15: 119-25.

24 Wong PF, Kumar S, Bohra A, Whetter D, Leaper DJ. Randomized clinical trial of perioperative systemic warming in major elective abdominal surgery. Br. J. Surg. 2004; 94: 421-6.

25 Horn E-P, Schroeder F, Gottschalk Sessler DI, Hiltmeyer N, Standl T, Schulte am Esch J. Active warming during cesarean delivery. Anesth. Analg. 2002; 94: 409-14. 